\title{
Concrete in high-rise buildings: practical experiences in Madrid
}

\author{
H. Corres Peiretti and M. Gómez Navarro
}

The use of concrete in high-rise buildings has increased significantly in the last 20 years mainly owing to improvement in all of the technologies associated with this material: admixtures, pumping, transportation and elevation methods, etc. These enhanced possibilities are illustrated by means of four high-rise buildings that were built recently in Madrid, each about $250 \mathrm{~m}$ high. The main structural elements of these buildings are presented focusing on the advantages offered by concrete compared to other materials that are commonly used in high-rise construction. The types of concrete considered are high-resistance concrete up to $\mathrm{C} 80$, selfcompacting concrete, precast and in situ concrete, reinforced or prestressed concrete, as well as normal weight or lightweight concrete. These examples clearly show that, even in structures where the role of self weight is determinant, concrete can be the best solution if all of the different factors involved in the success of a construction site are considered: geometry, ease of construction, means of elevation, prefabrication at factory, repetitiveness, material costs, control requirements, and so on.

[doi: 10.1680/stco.2010.11.2.83]

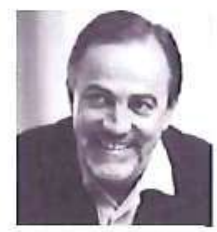

Hugo Corres Peiretti

FHECOR, Ingenieros

Consultores, Madrid

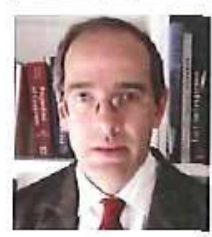

Miguel Gómez

Navarro

MC-2, Estudio de

Ingeniería, Madrid

\section{Introduction}

During the last decades of the twentieth century and what has so far transpired of the twenty-first century, a new and exciting explosion in the design and construction of high-rise buildings has taken place. The speed with which the height of buildings is growing has greatly increased. While the maximum height attained during the twentieth century was of the order of $500 \mathrm{~m}$, during the next few years this value is likely to be more than doubled, with credible projects achieving heights of about $1200 \mathrm{~m}$. Concrete, with its new performance features, presents itself as an ideal material in view of solving some of the problems of this type of structure, especially for medium heights. fib is about to form a new task group in order to bring together the experience gathered in the last few years and to study the new challenges involved in the use of structural concrete for this type of building (Corres et al., 2008).

In Madrid, four towers, each about $250 \mathrm{~m}$ high, were finished in the summer 2008. All of them have been built close together and have similar heights and plan sizes (Figure 1). The architects and structural design companies involved in their design and construction were

(a) Torre Caja Madrid: architect, Foster and Partners, London (UK); structural engineer, Halvorson and Partners, Chicago (USA), ARQUING, Madrid (Spain) (Lakota and Alarcón, 2008)

(b) Torre Sacyr-Vallehermoso: architect, Rubio and Álvarez-Salas, Madrid (Spain); structural engineer, MC2, Madrid (Spain) (MartinezCalzón and Gómez Navarro, 2008a)

(c) Torre de Cristal: architect, Pelli Clarke Pelli Architects, New Haven (USA); structural engineer, OTEP Internacional, Madrid (Spain); technical assistance to the construction company, FHECOR, Madrid (Spain) (Blanco et al., 2008)

(d) Torre Espacio: architect, Pei, Cobb, Freed and Partners, New York (USA); structural engineer, MC2, Madrid (Spain) (MartinezCalzón and Gómez Navarro, 2008b).

In all of them structural concrete has been widely used together with steel and composite elements. Different types of concrete have been used depending on the structural element and tower considered
(a) cast-on-site or precast
(b) normal density or lightweight
(c) normal or high strength
(d) normal workability conditions or self- compacting
(e) reinforced or prestressed

(f) pretensioned or post-tensioned with bounded or unbounded strands.

The main characteristics of the structures are described in the current paper, focusing on the advantages offered by concrete compared to other materials commonly used in high-rise construction. All structural designs were carried out in compliance with the Spanish national standards.

\section{Foundations}

The foundations of high-rise buildings have generally been designed using structural concrete. However, new possibilities for concrete offer alternatives that have not been used extensively up to now. Some of the advantages that have been used in these towers are

(a) the use of self-compacting concrete in foundation mats with very dense reinforcement

(b) the use of prestressing that allows the transmission of very large concentrated loads to distribute the ground pressures under the foundation mats, the reduction of passive reinforcement density ano adequate crack control (Figure 2); prestressing is also used in the pile caps of deep foundations with a large number of piles or very large pile diameters.

\section{Columns}

In the towers, concrete columns or composite 


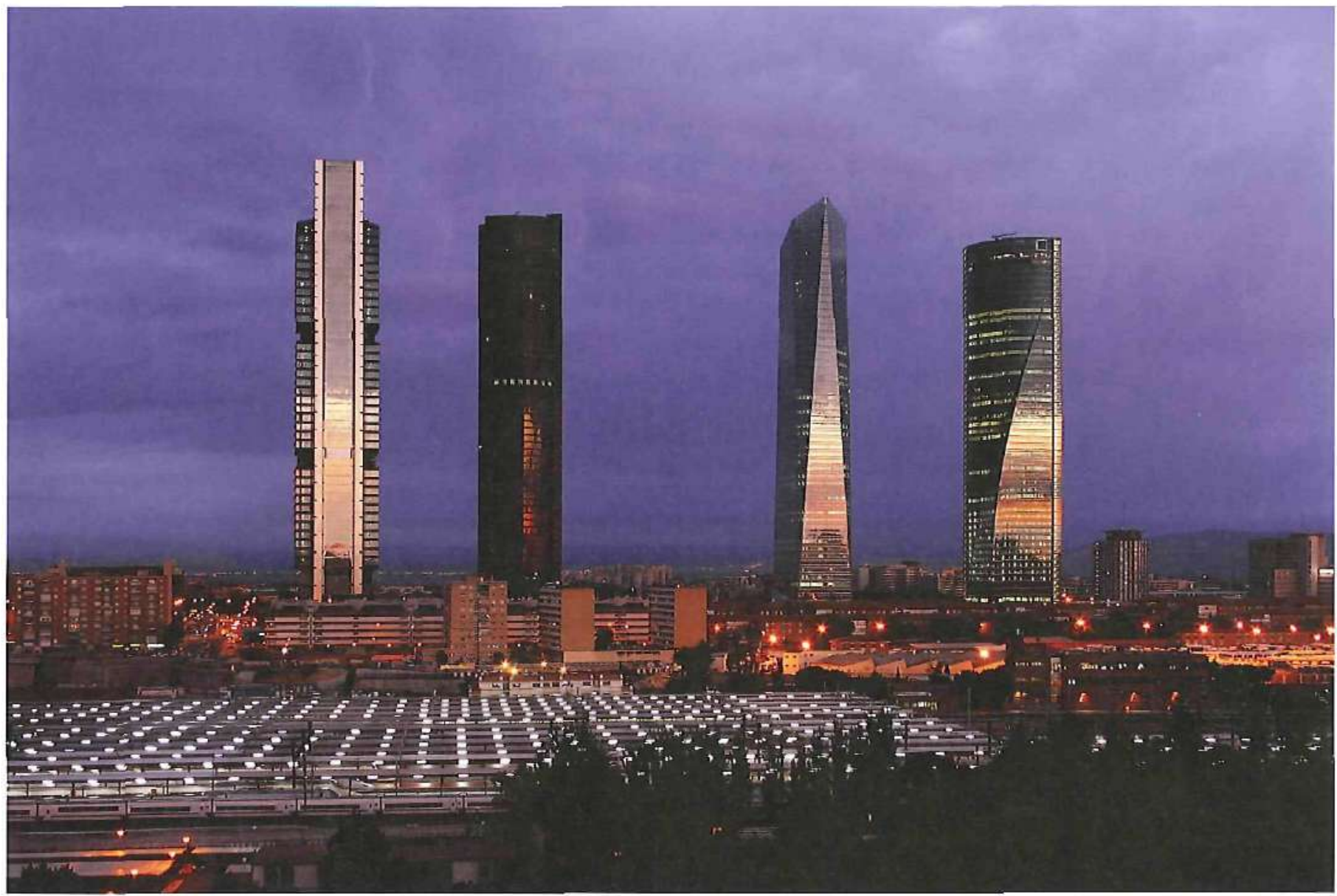

$\triangle$ Figure 1 General view of the four towers. From left to right: Torre Caja Madrid, Torre Sacyr-Vallehermoso, Torre de Cristal and Torre Espacio (courtesy of Dragados).

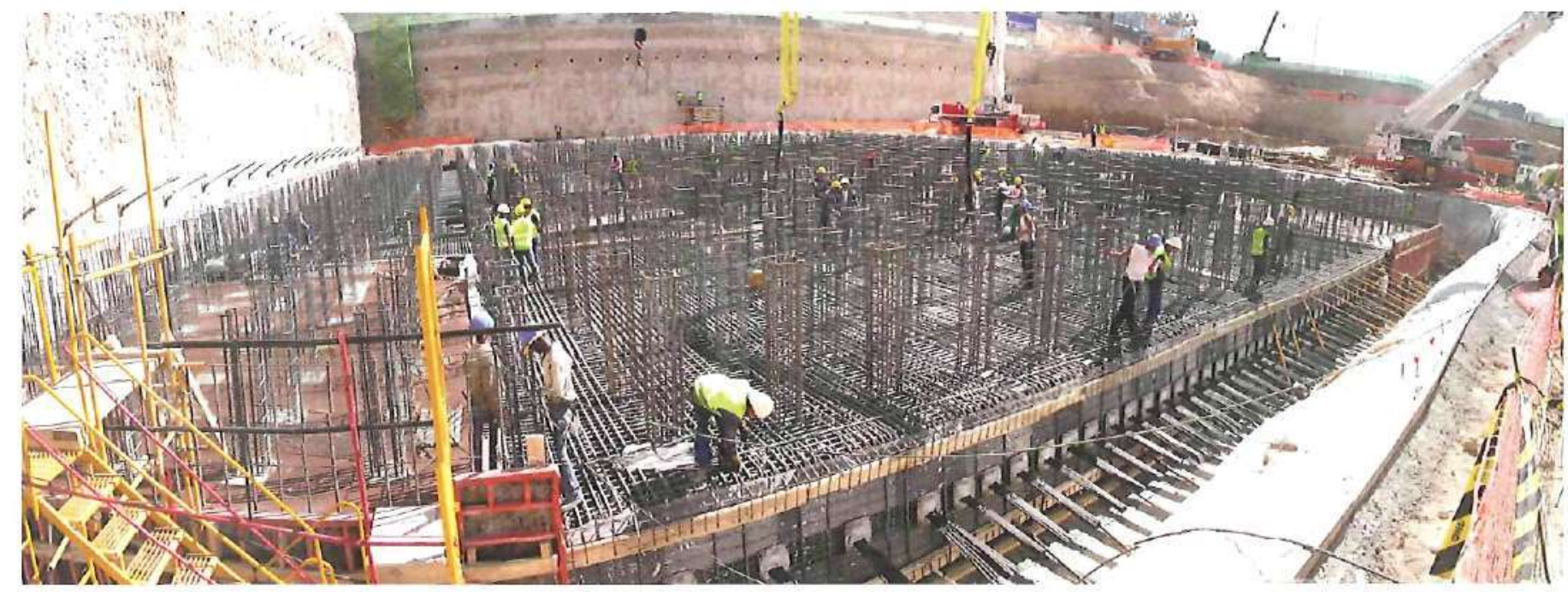

$\triangle$ Figure 2 General view of the foundation mat at Torre Espacio including the prestressing cables 
columns have been used, except for in the case of Torre Caja Madrid. The use of steel profiles embedded in the composite columns in Torre Sacyr Vallehermoso simplifies the construction of the composite slabs, because a standard bolted connection between columns and steel beams of the slab can be used. The use of reinforced concrete, reaching a C70 grade (all concrete strength classes refer to cylinder strength) up to level $+140 \mathrm{~m}$, made it possible to reduce unit costs significantly owing to its higher resistance/cost ratio compared to structural steel (Figure 3 ). The connection between sections of the steel columns was quite simple, as the bolted connection had to resist the tensile forces due to wind only during construction. The compressive forces resisted by the steel profiles are transmitted simply by contact between them, whereas the tensile forces in the composite section are resisted only by the reinforcement. Steel profiles used are 5355 grade and their maximum size is HEM 300 . In spite of the significant concentration of reinforcement bars and the incidence of the lap length (almost one-third of the reinforcement corresponds to lapping reinforcement), mechanical connections were avoided because of their higher cost.

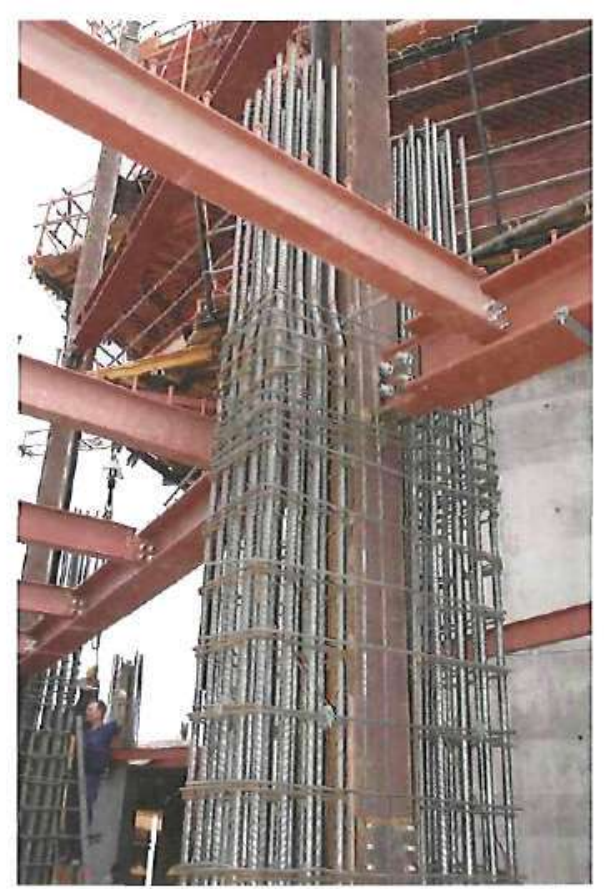

$\triangle$ Figure 3 Torre Sacyr-Vallehermoso: composite column before concreting
In the perimeter columns of Torre de Cristal ('glass tower'), which are working mainly as compression members, a composite cross-section with a constant diameter of $0.95 \mathrm{~m}$ has been used. The column is filled with selfcompacting C -45 grade concrete and reinforced with steel profiles of decreasing area as height increases. In the lower floors, steel profiles of type HD with Histar $\$ 460$ steel and varying thickness of up to $120 \mathrm{~mm}$ were used (Figure 4).

Owing to the unusually large thickness of the profiles and the need to speed up the construction, the profiles were considered solely as compression members working by contact. In order to resist tension forces due to local bending between floors, only the resistance of ordinary reinforcement bars was considered.

From the point of view of construction, it became necessary to devise a coupling system for the successive columns' fragments, which would guarantee conditions of flatness and perpendicularity in order to minimise contact problems between two successive column parts. The steel profiles were built in parts, spanning three floors, and were lifted into position with the reinforcement already in place (Figure 5). Self-compacting concrete

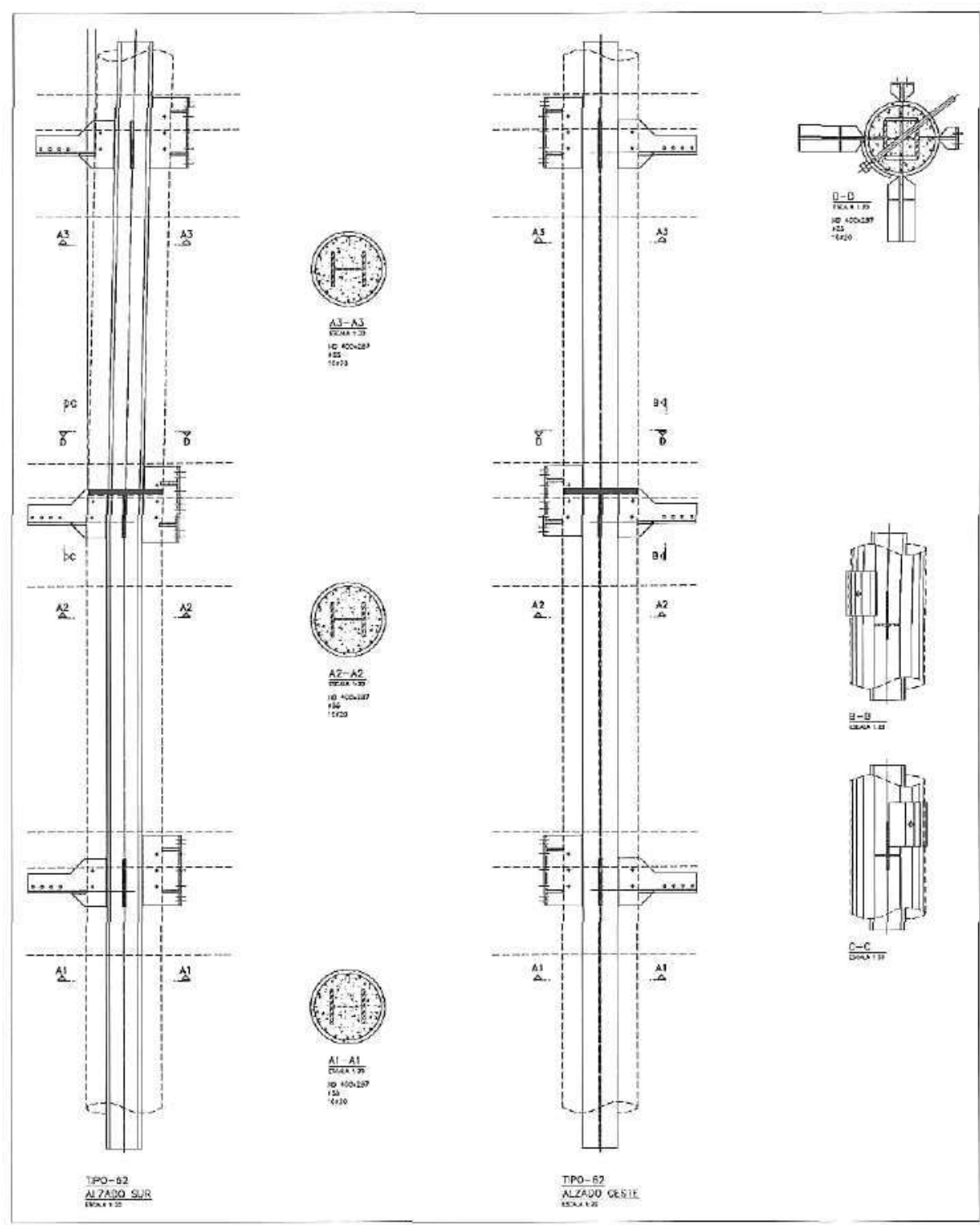

$\triangle$ Figure 4 Torre de Cristal: elevation view of the steel profiles embedded in the reinforced concrete columns (column cross-section also shown) 

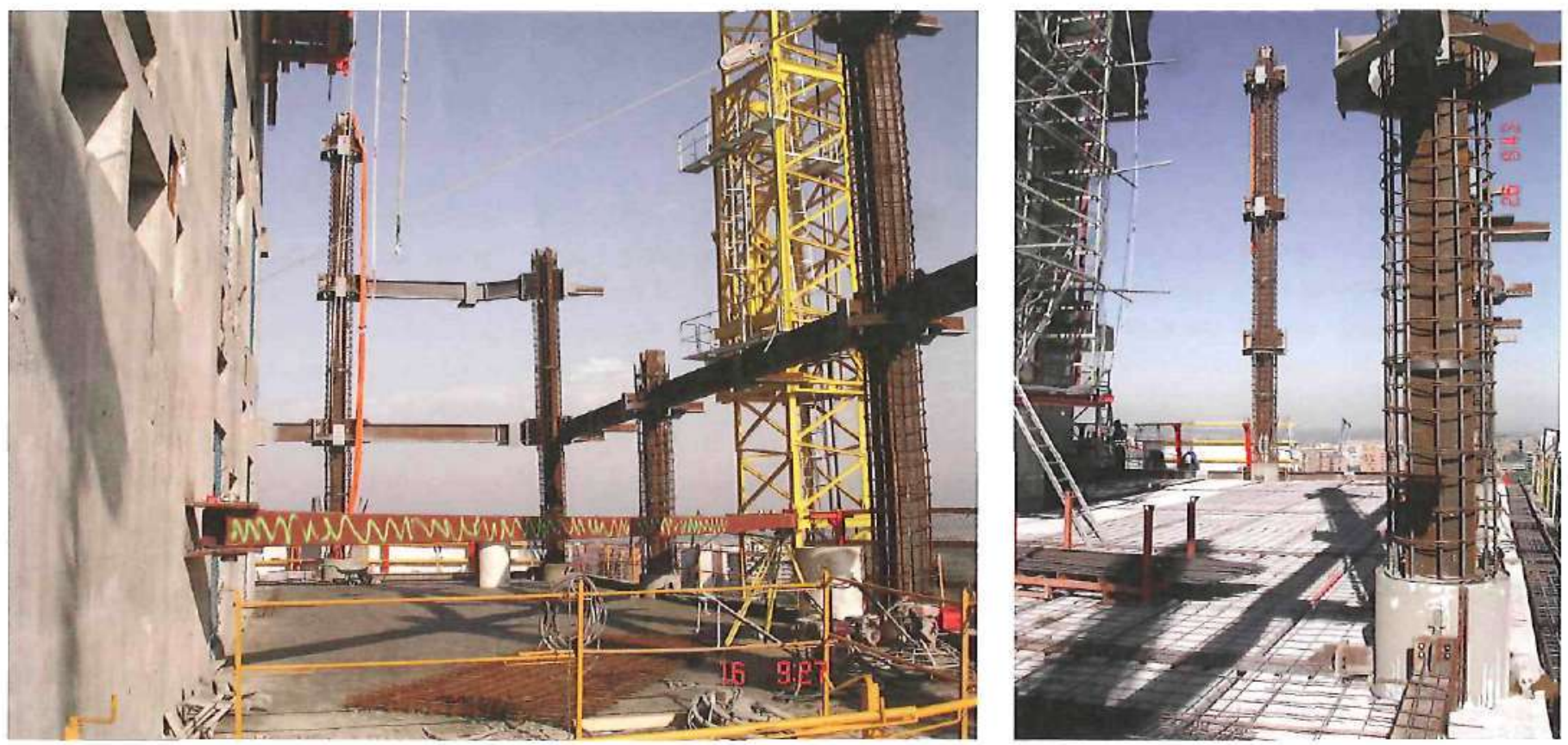

\section{$\triangle$ Figure 5 Torre de Cristal: assembly of the composite columns}

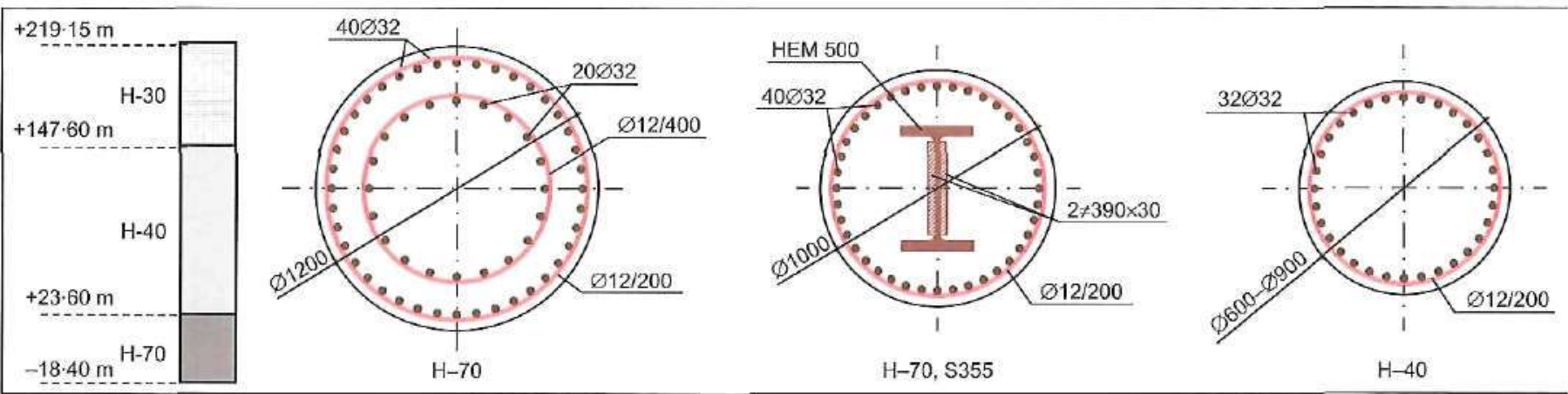

$\triangle$ Figure 6 Torre Espacio: variation of the concrete grade along the height of the tower and typical cross-sections of the columns

was important in order to minimise concreting problems, given the great density of reinforcement and the presence of the steel profile. In this case the required concrete strength was not very high (C-45).

The use of composite columns with highstrength concrete minimises the effect of the differential vertical displacement between the columns and the central core. Structural steel reduces time-dependent strains of the concrete and high-strength concrete shows smaller time-dependent strains than conventional concrete. This design therefore results in a reduction of the difference in vertical displacements between the columns located along the building perimeter and the stiffening core.
Mainly reinforced concrete columns were used in Torre Espacio. C-70 concrete grade was used in the lower floors, but was reduced above level +24.00 to $C-40$ and $C-30$ (Figure 6). A detailed analysis was carried out to determine the best solution for the columns; this analysis included unit costs, influence on the construction speed and architectural requirements. In the underground floors the main columns are 1200 $\mathrm{mm}$ in diameter and have two rings of $32 \mathrm{~mm}$ reinforcement bars. By contrast, in the access area where architectural requirements were tighter, steel profiles were embedded in the columns to reduce their dimensions: $\$ 355$ steel, C-70 concrete and reinforcement bars were used (Figure 7). Special attention was paid to detailing of the connection areas between column sections and to the intersection with the slabs, In some areas with a significant concentration of reinforcement bars and mechanical couplers, high-strength mortar was used instead of concrete. In the intersection zone between columns and slabs, openings were provided in the webs of the steel profiles to enable the passing of the reinforcement bars.

A detailed study was also carried out to evaluate the incidence of differential settlements between the cores and the columns. This study considered the influence of the construction process, the average permanent 

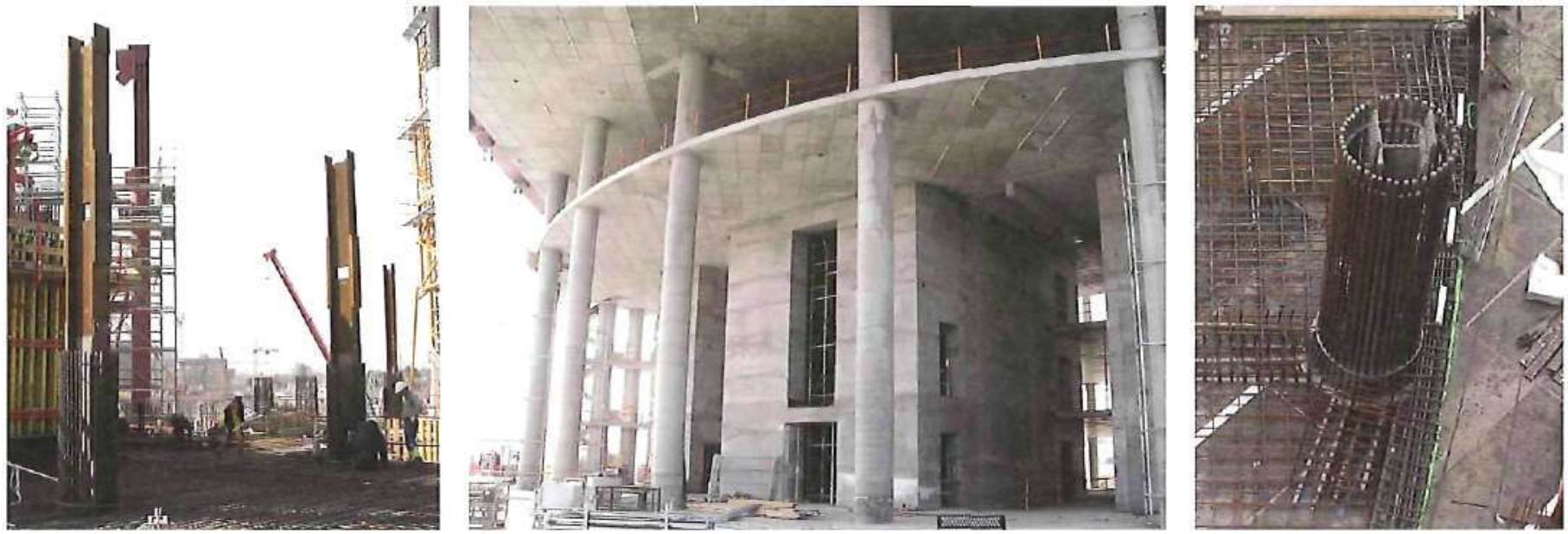

$\triangle$ Figure 7 Torre Espacio: composite columns at the base of the tower

compressive stresses that can be very different depending on the type of core or column considered, and the different rheological properties between all the materials. The significant scatter that is associated with these parameters was also taken into account. This study was particularly important to evaluate the influence on the behaviour of the façade owing to the peculiar geometry of the building and the variable set-up of the supports (Figure 8).
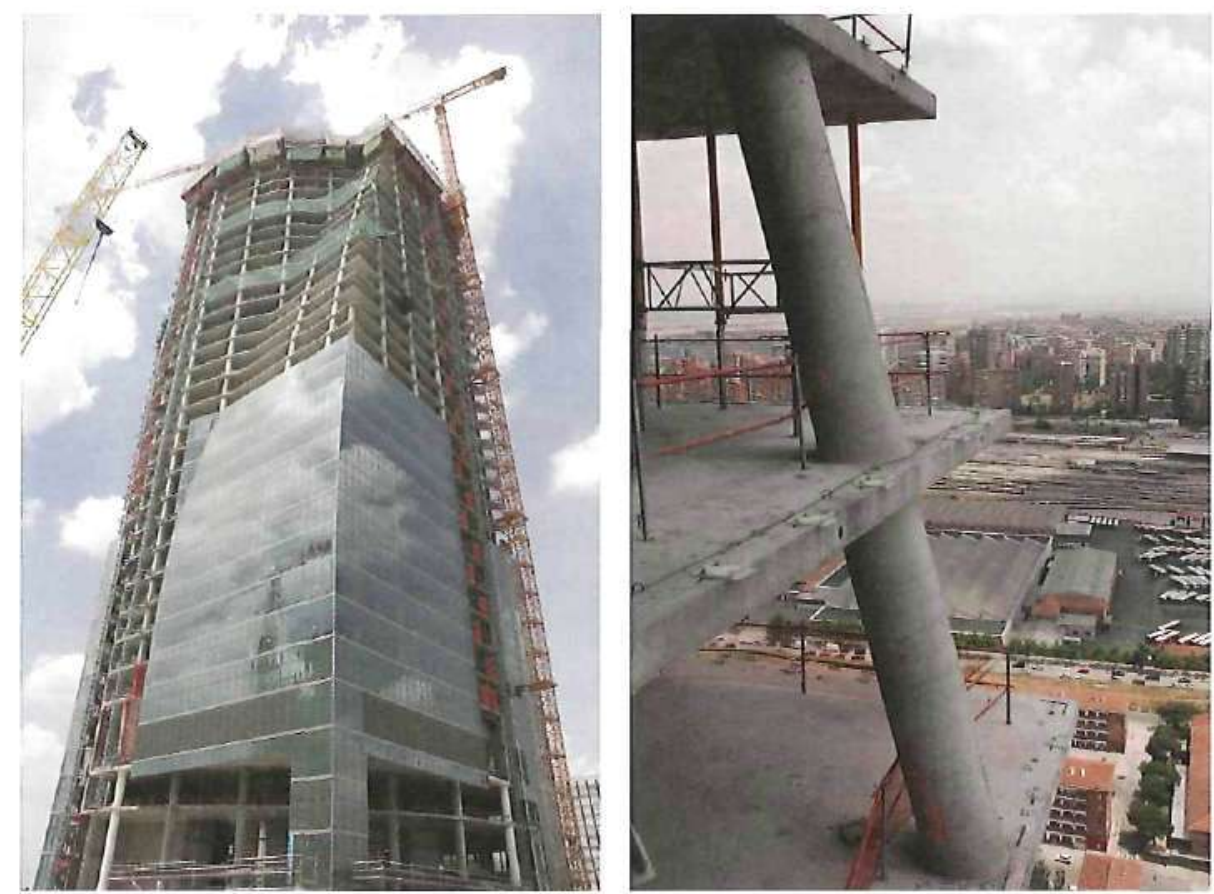

$\triangle$ Figure 8 Torre Espacio: inclined columns that disappear in the upper floors the permanent loads on the supports and cores. The use of supplementary reinforcement bars in the span regions of the composite slab in Torre Sacyr-Vallehermoso avoided the need of additional fireproofing materials to reach the required R-180 fire resistance. The construction system used, which combines the advantages of steel and concrete structures, enabled the construction speed to be maintained at one floor per week with moderate costs and level of complexity (Figure 9).

In the Torre de Cristal an original system involving a composite horizontal structure coupled with precast hollow-core slabs was designed. This solution was adopted because the available means of elevation were compatible with the placing of the hollow-core slabs and because it was decided that this solution would increase construction speed (Figure 10). With this system, one floor could be built within 1 week. Compared to a steel or composite solution, fire protection requirements and total static depth could be reduced, as only the lower flanges of the beams had to be fireproofed.

In Torre Espacio the geometry of the floors varies continuously along the height. The $280 \mathrm{~mm}$ thick solid reinforced concrete slabs that have been used easily follow this variation, resulting in a rhythm of construction of three or four slabs per month. Prestressing has been avoided owing to the curved shape of the floor and the abundant presence of shafts that make the cable and anchorage layout quite difficult. The 

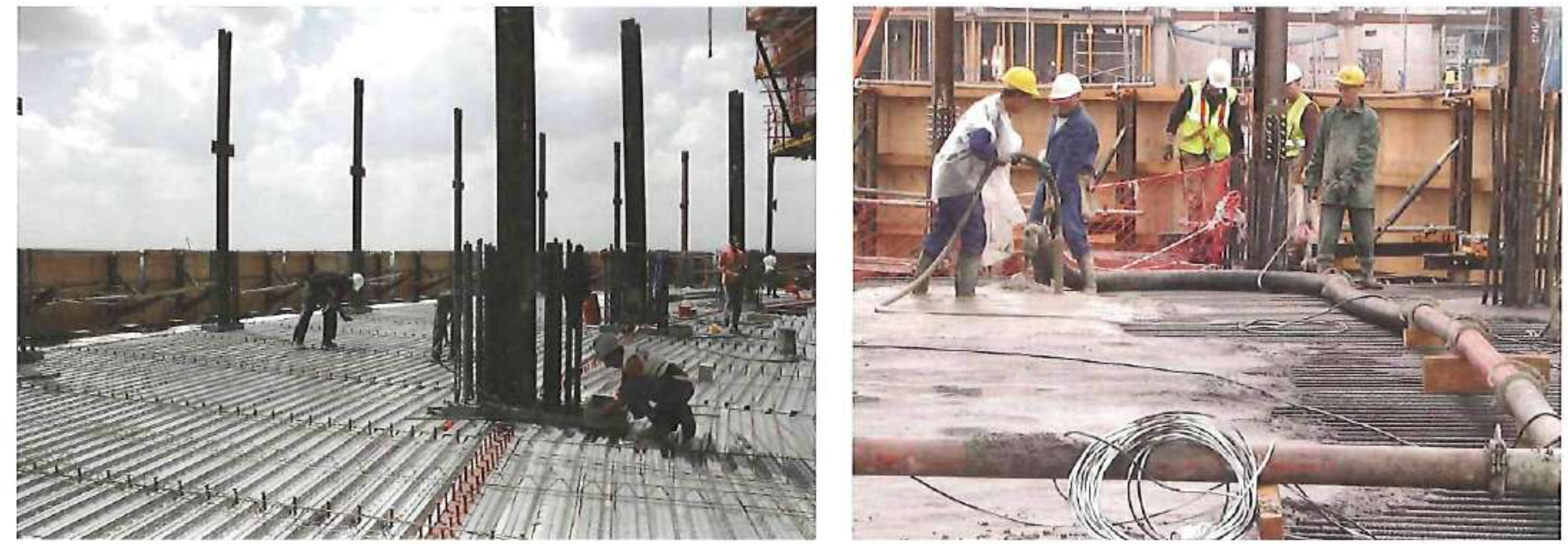

$\triangle$ Figure 9 Torre Sacyr-Vallehermoso: assembly and concreting of the composite slab

intersection between the columns and the slabs, when they are made with different concrete grades, is solved by using confinement reinforcement. This reinforcement, made by five circular stirrups consisting of $25 \mathrm{~mm}$ bars, increases the slab concrete resistance $(C-30)$ up to the value required by the columns (C-70) (Figure 11). With this solution the concreting of the slabs was greatly simplified because it could be carried out in a single operation.

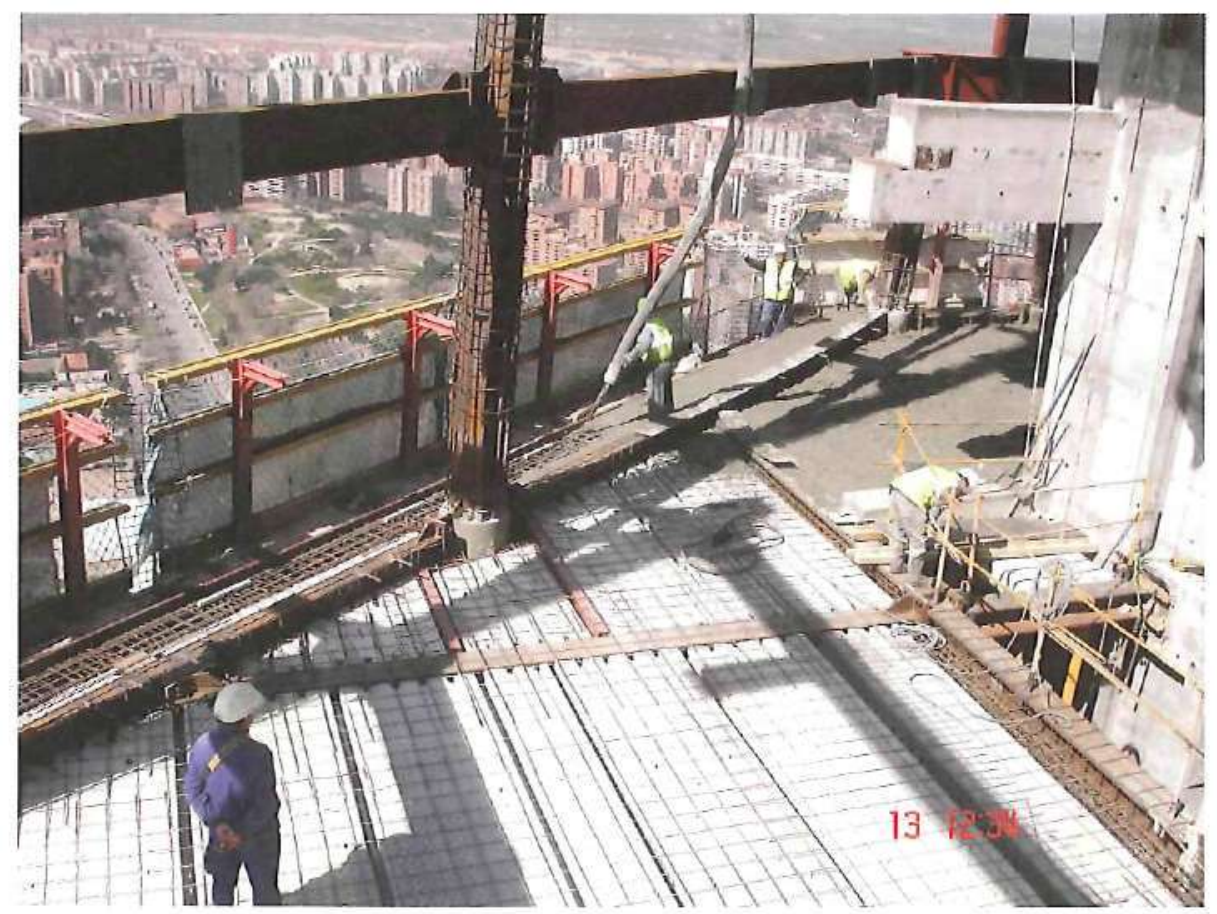

$\triangle$ Figure 10 Torre de Cristal: hollow-core slab solution for the floor structure

\section{Wind-resistant elements}

According to relevant codes, no seismic forces need be considered in the design of buildings to be built in Madrid. Therefore, the only horizontal forces considered were those due to wind; these were determined for the four towers by means of wind tunnel tests carried out at the boundary layer wind tunnel laboratory at the University of Ontario (Canada) (Figure 12).
In Torre Caja Madrid, the wind-resisting elements are two reinforced concrete cores located at each side of the tower, which also carry all the vertical loads. Also in Torre de Cristal, the horizontal loads are resisted solely by means of the core, which in this case is a single one located at the centre of the tower and designed in reinforced concrete. As is usual in this type of element, lots of openings are required in the walls of the cores for reasons of building functionality.

In both Torre Sacyr-Vallehermoso and Torre Espacio, some concrete structural elements collaborate with the reinforced concrete cores in resisting the wind forces. The dimensions of the three-lobed central core in Torre Sacyr-Vallehermoso are sufficient to resist $90 \%$ of the wind loads, requiring the collaboration of a simple outrigger that can be located at the top of the building, although this is not the optimal position (Figure 13).

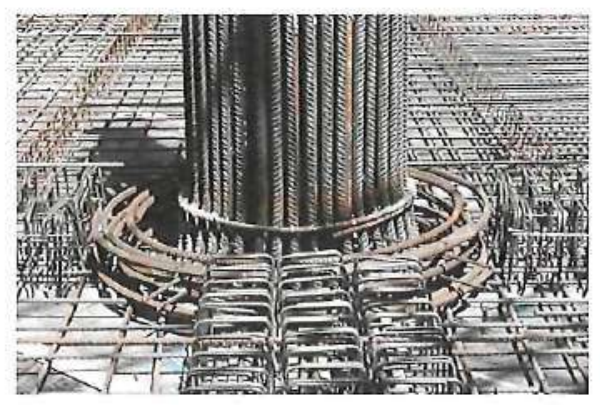

$\triangle$ Figure 11 Torre Espacio: confinement with reinforcement at the intersection between slabs and columns with different concrete grades 


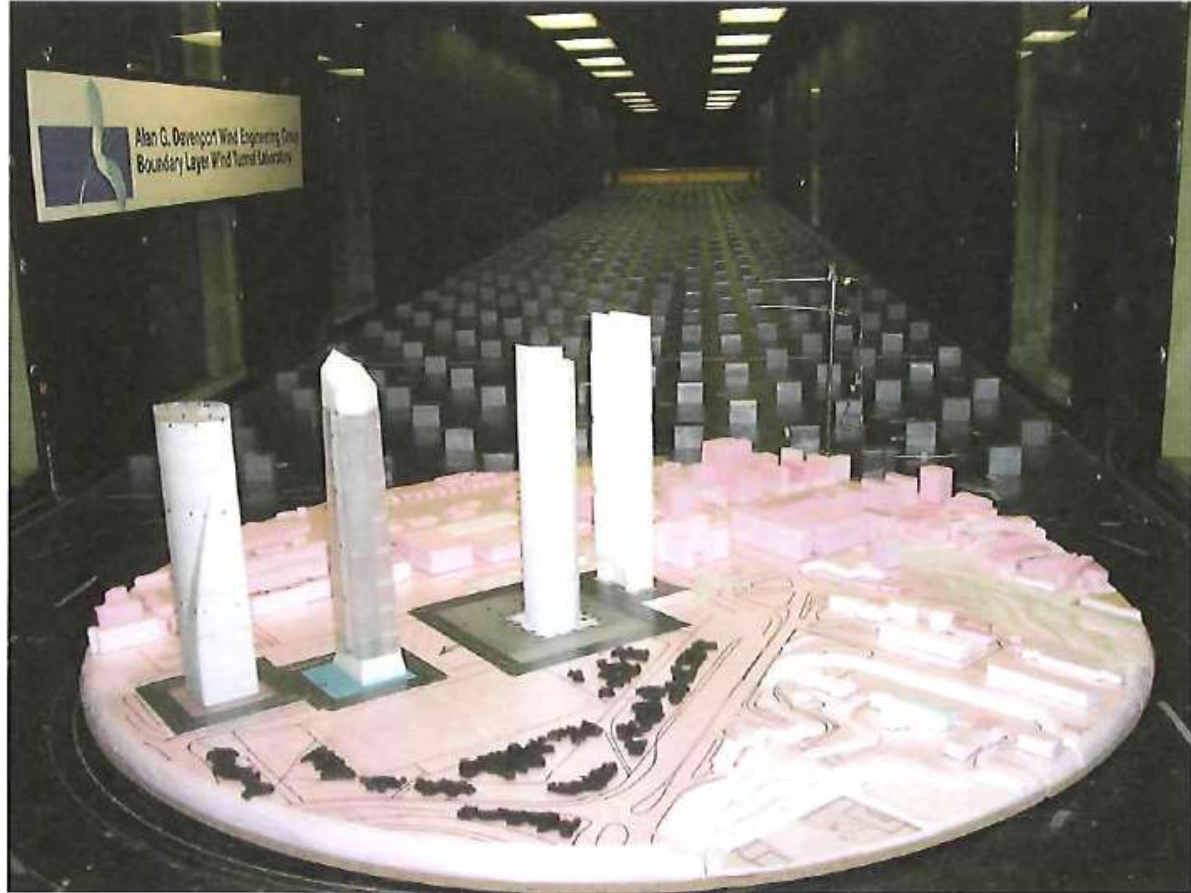

$\triangle$ Figure 12 Boundary layer wind tunnel tests of the four towers at the University of Western Ontario, Canada

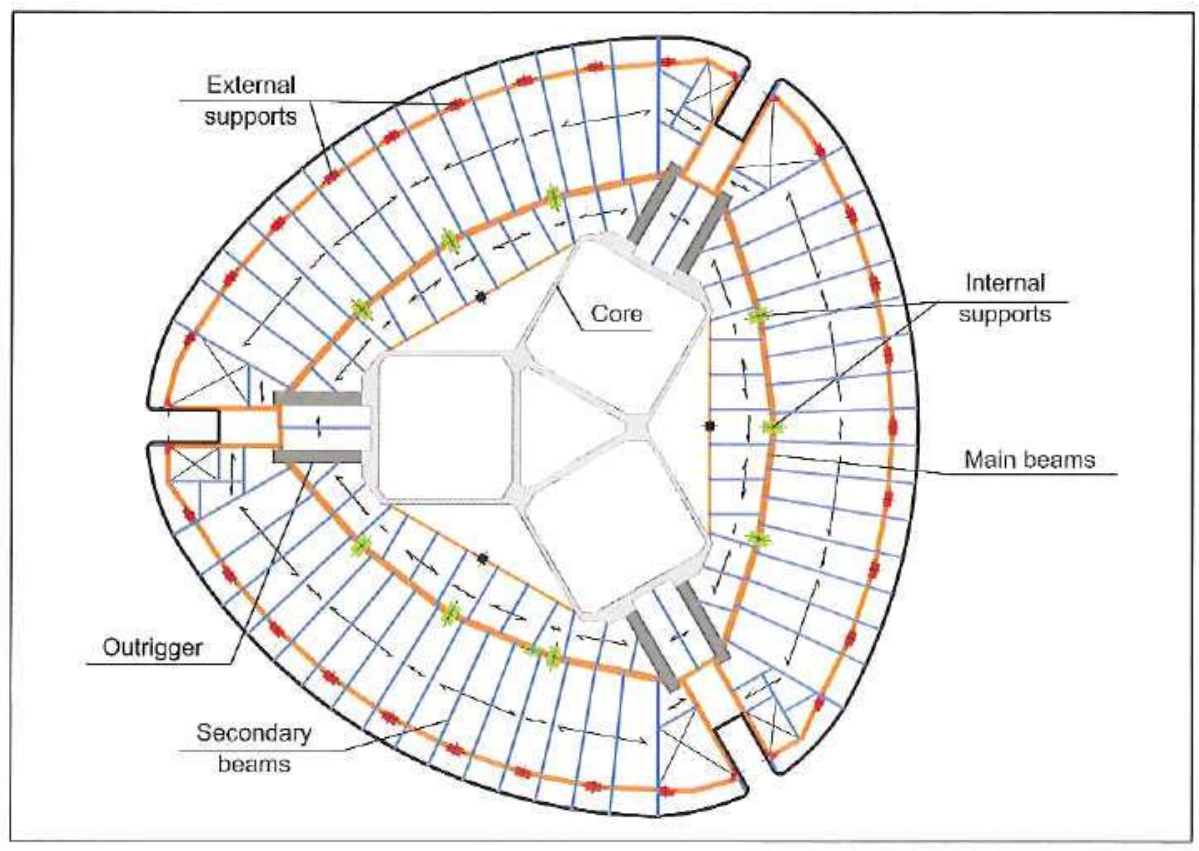

$\triangle$ Figure 13 Torre Sacyr-Vallehermoso: reinforced concrete central core and outrigger at the top of the building

The designs of the core and the outrigger were strongly determined by the presence of shafts in the tower, as only a small portion of the vertical loads are transferred to the core, thereby losing the beneficial effect that these forces have on an element that must resist mainly bending moments.

In Torre Espacio, the main central core is combined with two secondary lateral cores that disappear at intermediate heights with the lower groups of elevators. These cores have been designed in reinforced concrete and have been built with self-climbing formworks. Additionally, an important outrigger has been built at two-thirds of the height of the tower, in a floor occupied by mechanical instruments and equipment. This outrigger connects ten main columns with the central core by means of a group of longitudinal and transversal walls connected to the upper and lower slabs, creating a very efficient spatial grid (Figure 14). Owing to the high values of the forces that must be transferred by the structure, prestressing cables had to be included in the slabs (units included up to 19 cables with a diameter of 0.6 in (15 mm)) and the walls (Figure 15). Also, the high compressive forces that must be resisted by the slabs required the use of C-80 concrete. Detailed studies were carried out by the construction company to ensure the pumpability of this special type of concrete that normally is used in elements and heights that do not require the use of pumps. Concrete was preferred to steel for the design of this outrigger because of the high self weight of the steel elements required, which resulted in greater construction complexity. Also, the stiffness of a concrete outrigger is significantly higher than that of a steel or composite one, despite the influence of openings for shafts, doors and pipes.

The numerical analysis carried out during the project showed the influence of the outrigger in the distribution of gravity loads due to both instant and long-term behaviour. As a consequence, almost $50 \%$ of the forces resisted by the outrigger were originated by gravity.

The main advantage of the reinforced concrete slabs used in Torre Espacio is that they contribute to the overall wind-resistant behaviour of the tower without a significant increase in the reinforcement required. Even their individual stiffness is not significant; all of them combined and rigidly connected to the central core are able to transfer more than $30 \%$ of the wind load to the columns that resist these horizontal loads, with tensile or compressive forces that do not increase the design values owing to maximum gravity loads. 


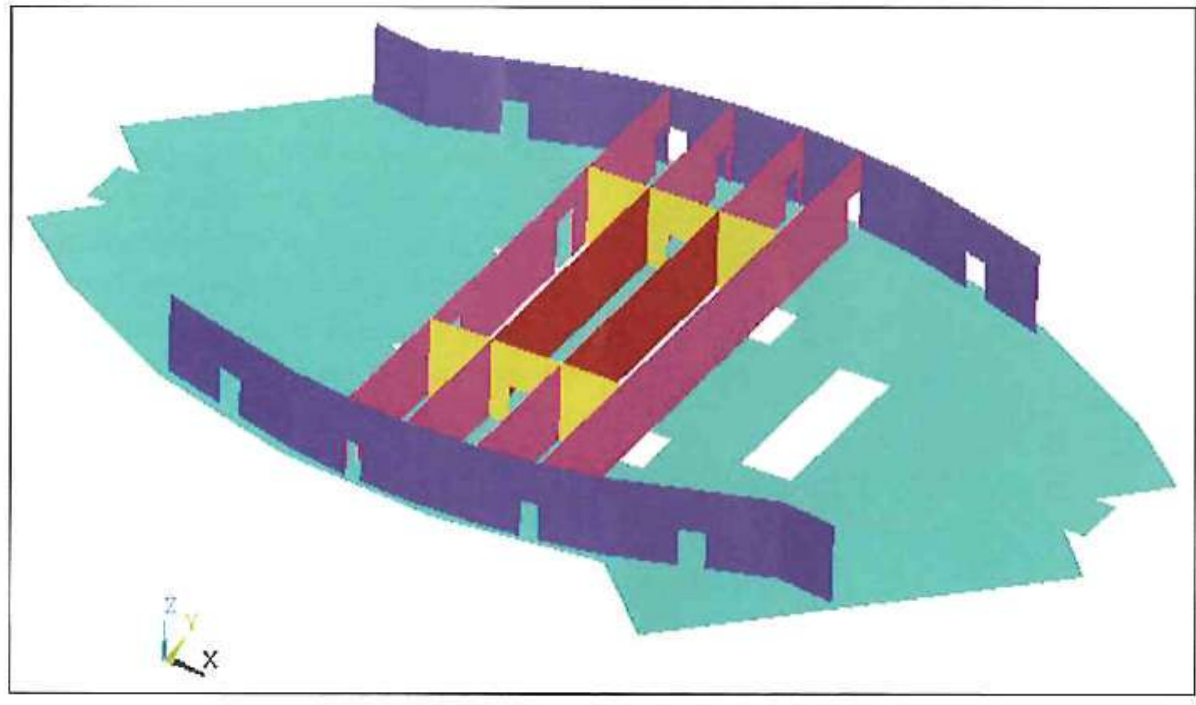

$\triangle$ Figure 14 Torre Espacio: outrigger connecting columns and central core

\section{Transfer elements for vertical loads}

In this type of building, it is common for some supports to be removed in lower floors in order to enhance the functionality of the access areas. As the loads are especially high, supports, being connected at the top by means of a powerful tie (Figure 16). These struts and ties were designed as composite members similar to the composite columns of the tower, even though the higher values of the forces to be resisted required a higher use of structural steel and reinforcement. Detailed analyses were carried out for the force transfer at the nodes and between the different structural materials.

In the case of Torre Espacio, this situation is present in the lobby area and has been solved with a pair of composite trusses having a static depth of $8 \mathrm{~m}$, equivalent to the two floors that correspond to the technical areas (information technology suites) located over the entrance lobbies. The chords and diagonals of these trusses are steel boxes, but the chords are connected to the concrete slabs to improve the behaviour of the structure. The diagonals include some prestressing cables to reduce the size of the steel section and to improve the control of the deflections of the trusses and the façades affected by them. The outer vertical supports are embedded in a reinforced concrete support to improve their stability (Figure 17).

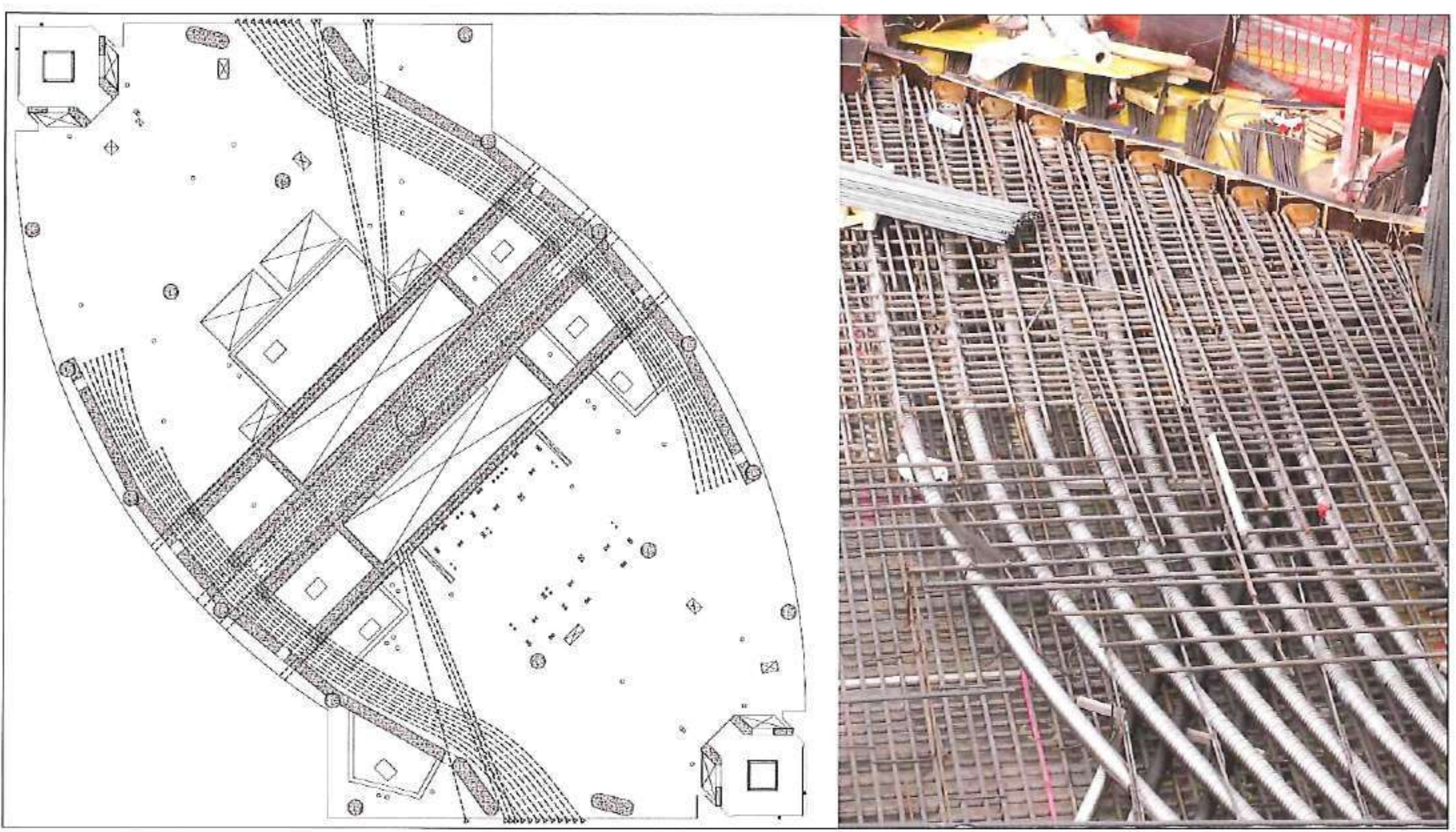

$\triangle$ Figure 15 Torre Espacio: prestressing layout at the outrigger slabs 

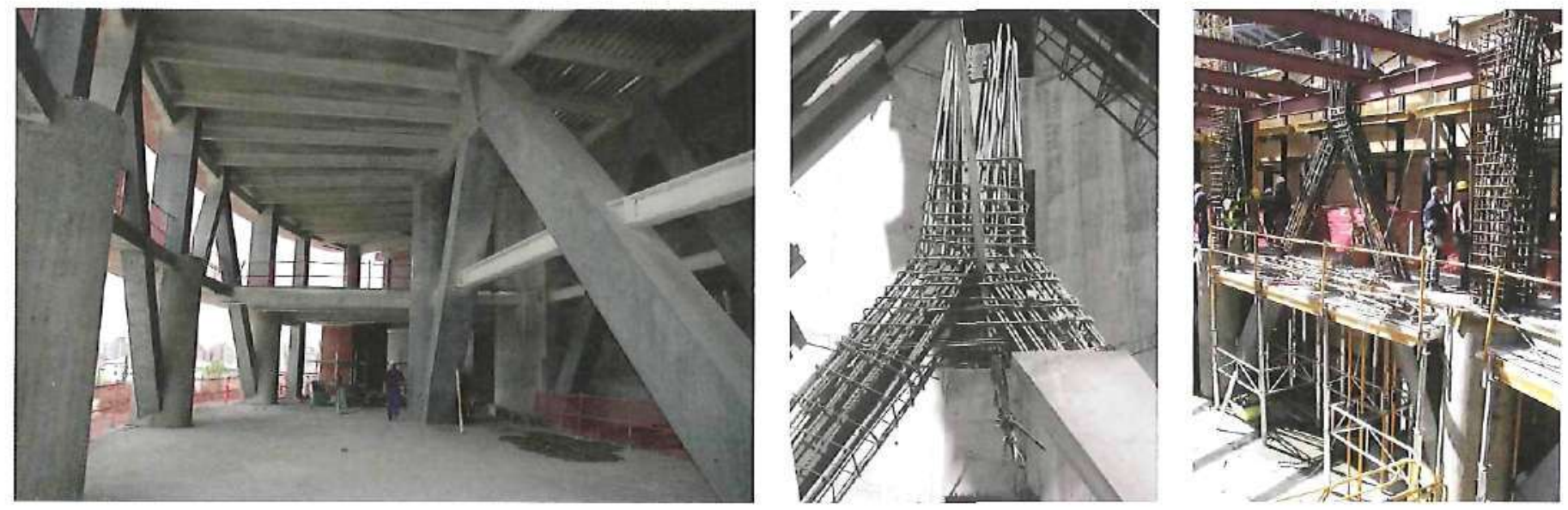

$\Delta$ Figure 16 Torre Sacyr-Vallehermoso: composite trusses to remove supports at the base of the tower

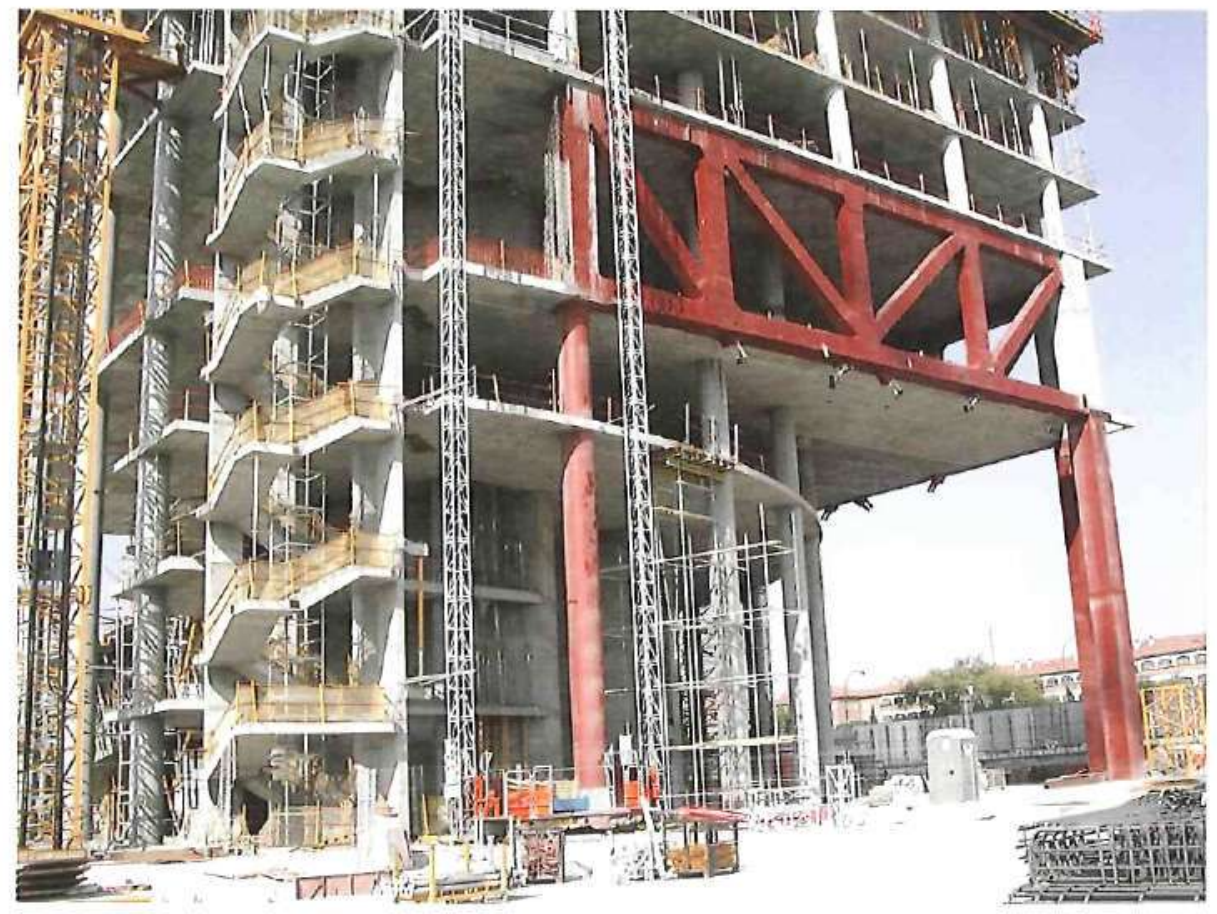

$\triangle$ Figure 17 Torre Espacio: composite trusses at the base of the tower

\section{Conclusion}

The new possibilities of concrete from the point of view of strength, technology and construction demand a review of possible applications of this material in all existing structural typologies and also, of course, in high-rise buildings.
The appropriate intelligent and creative use of the new types of concrete is widely extending the field of application of this material and is opening new design possibilities which have hitherto been unexplored. These possibilities have been illustrated with the examples of four towers built recently in Madrid, in which concrete in very different varieties has been used extensively. These towers show clearly that, even in structures where the role of self weight is dominating, concrete can be the best solution if all the factors involved in the success of a construction site are considered: geometry, ease of construction, means of elevation, prefabrication at the factory, repetitiveness, material costs, control requirements, and so on.

\section{References}

Blanco Temprano PJ, Herrera Castilla C and Viñals JI (2008) Torre de Cristal. Structural design for a high rise building. Hormigón y acero 59(249): 71-87.

Corres H, Romo J and Romero E (2008) High rise buildings. The challenge of a new field of possibilities for the use of structural concrete. In Tailor Made Concrete Structures (Walraven JC and Stoelhorst $R$ (eds)). Taylor and Francis, London, p. 182.

Lakota G and Alarcon A (2008). Torre Caja Madrid: structural design of a singular $250 \mathrm{~m}$ building in Madrid. Hormigón y acero 59(249): 181202.

Martínez Calzón J and Gómez Navarro M (2008a) Torre Sacyr-Vallehermoso. Building structure. Hormigón y acero 59(249): 123-150.

Martínez Calzón J and Gómez Navarro M (2008b) Torre Espacio. Building structure. Hormigón y acero 59(249): 19-43. 